\title{
Structure and Liquid Crystalline Properties of Poly(azomethine-ester)s
}

\author{
Danuta SĘK \\ Institute of Polymer Chemistry, Polish Academy of Sciences, \\ 41-800 Zabrze, Poland
}

(Received April 9, 1984)

\begin{abstract}
A series of polyesters having azomethine groups in the main chain was synthesized and ability of the polymers to formation of thermotropic mesophase was investigated. KEY WORDS Poly(azomethine-ester)s/Liquid Crystals / Polycondensation /
\end{abstract}

One condition necessary for organic compounds to exhibit thermotropic liquid crystalline properties is the molecule with rod-like or disc-like structure. It is known that such structures cause an increase in the melting point of a compound. This is also the case for polymers but polymers may start to decompose before reaching the melting point. One method for lowering the high melting points of rod-like polymers is the introduction of flexible aliphatic units into their chains. This may also be achieved by using monomers with pendant groups but it should be kept in mind that the behavior of the pendant groups is made complicated by steric and polar effects. ${ }^{1,2}$ Steric effects generally results in reducing the thermal stability of the mesophase. On the other hand, substituted units, in which the pendant groups impart on increased polarizability and stronger dipolar interactions between the mesogenic groups, can have stronger intermolecular attractions, which would lead to higher thermal stabilities of both the crystalline and liquid crystalline phases.

In this work, both these methods were used and the influence of the structure of the rodlike monomer and the length of the aliphatic chain in the polymer on the melting point and mesomorphic temperature range are discussed. The polymers were obtained by polyconden- sation of two series of dihydroxy-azomethine compounds with aliphatic diacids: sebacic and decanoic.

\section{EXPERIMENTAL}

\section{Monomers}

Dihydroxyazomethine compounds were synthesized in the reaction of 4-hydroxybenzaldehyde $(0.2 \mathrm{~mol})$ or vanillin $(0.2 \mathrm{~mol})$ with the proper diamine $(0.1 \mathrm{~mol})$ in boiling toluene $(500 \mathrm{ml})$ and in the presence of $p$ toluenesulfonic acid $(0.05 \mathrm{~g})^{3,4}$ The crude product was crystallized from $n$-butyl alcohol. Some properties of the dihydroxyazomethine compounds whose structures were confirmed by mass spectroscopy, elemental analysis, IR and UV spectra are given in Table I.

Sebacoyl dichloride was synthesized by a reaction of sebacic acid with an excess of thionyl chloride and distilled before use. Dodecanedioyl dichloride was prepared by the reaction of diacid with oxalyl chloride.

\section{Model Compounds}

Model compounds were synthesized by the reaction of the dihydroxyazomethine compounds $(0.0025 \mathrm{~mol})$ with benzoyl chloride $(0.005 \mathrm{~mol})$ in dichloromethane $(20 \mathrm{ml})$ in the presence of triethylamine $(0.005 \mathrm{~mol})$. The 
Table I. Properties and UV maximum absorption bands, $\lambda_{\max }(\mathrm{nm})$ of dihydroxyazomethine compounds

\begin{tabular}{|c|c|c|c|c|c|c|c|c|}
\hline \multirow{2}{*}{ No. } & \multirow{2}{*}{$\mathrm{Ar}$} & \multirow{2}{*}{$\frac{\text { Yield }}{\%}$} & \multirow{2}{*}{$\frac{\text { Melting point }}{{ }^{\circ} \mathrm{C}}$} & \multicolumn{5}{|c|}{ UV maximum absorption bands/nm } \\
\hline & & & & $\mathrm{E}_{1}$ & $\mathrm{E}_{2}$ & B & $\mathrm{R}$ & $\mathrm{K}$ \\
\hline & & & & \multicolumn{5}{|c|}{$\mathrm{HO}-$ (O) $-\mathrm{CH}=\mathrm{N}-\mathrm{Ar}-\mathrm{N}=\mathrm{CH}-$ (O) $-\mathrm{OH}$} \\
\hline 1 & -(0) & 50.0 & $264-265$ & 205 & 225 & 287 & - & 357 \\
\hline 2 & (1) $(0)$ & 75.0 & $313-314$ & 206 & 220 & 290 & - & 350 \\
\hline 3 & & 67.6 & $285-286$ & 208 & 221 & 281 & 320 & 359 \\
\hline \multicolumn{9}{|c|}{ 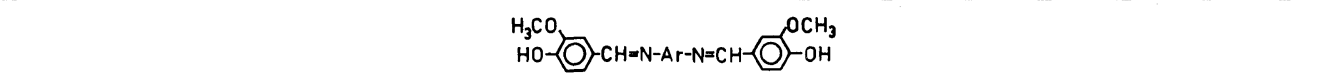 } \\
\hline 4 & -(a) & 80.0 & 194-197 & 207 & 236 & 287 & - & 363 \\
\hline 5 & (0)-(0) & 84.0 & $230-232$ & 207 & 232 & 288 & - & 360 \\
\hline 6 & (1) & 67.0 & $229-231$ & 210 & 235 & 283 & 322 & 360 \\
\hline
\end{tabular}

Table II. Phase transition temperatures of model compounds

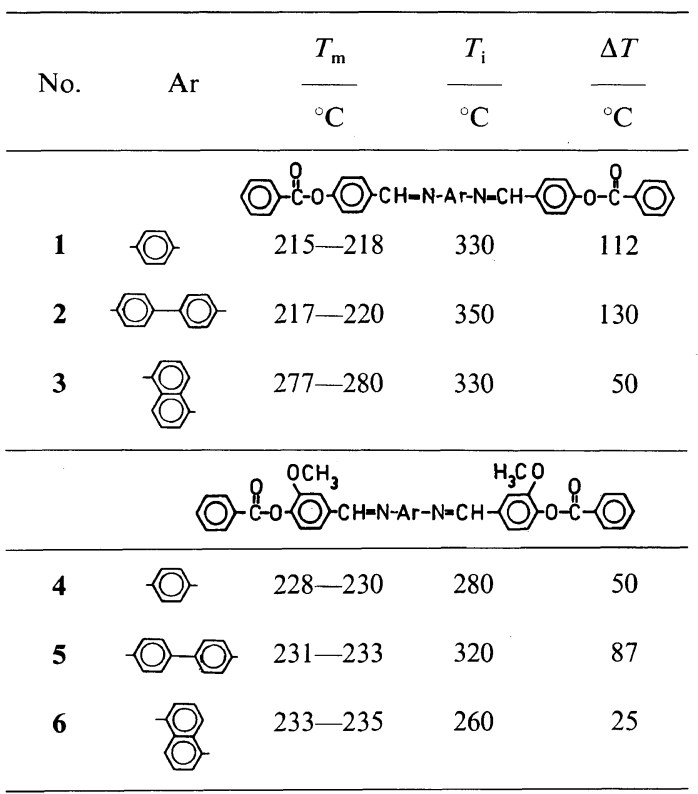

crude product was crystallized from anisol. Phase transition temperatures of the model compounds are shown in Table II.

\section{Polycondensation}

The polycondensation reaction was carried out by the low-temperature solution method as follows. Into $0.005 \mathrm{~mol}$ of a dihydroxyazomethine compound and $0.010 \mathrm{~mol}$ of triethylamine in $25 \mathrm{ml}$ of dichloromethane $0.005 \mathrm{~mol}$ of an acid chloride in $25 \mathrm{ml}$ of dichloromethane was added at $20^{\circ} \mathrm{C}$ over a period of $5 \mathrm{~min}$. After $3 \mathrm{~h}$ of stirring the reaction mixture was poured into $100 \mathrm{ml}$ of ethanol and filtered. The polyesters were dried and then extracted (Soxhlet apparatus) with boiling ethanol for $8 \mathrm{~h}$ and dried. The properties of the polymers are presented in Tables III and IV.

\section{Measurements}

Infrared spectra were taken in nujol with a UR-20 (Zeiss apparatus).

The UV spectra were measured in methanol at a concentration of $10^{-5} \mathrm{moll}^{-1}$ with a Specord (Zeiss apparatus).

The mass analysis was made using a LKB 9000 spectrometer, the energy of the electron beam was $70 \mathrm{eV}$ and the source temperature, 
Structure and Liquid Crystalline Properties of Poly(azomethine-ester)s

Table III. Properties of sebacic acid polyesters

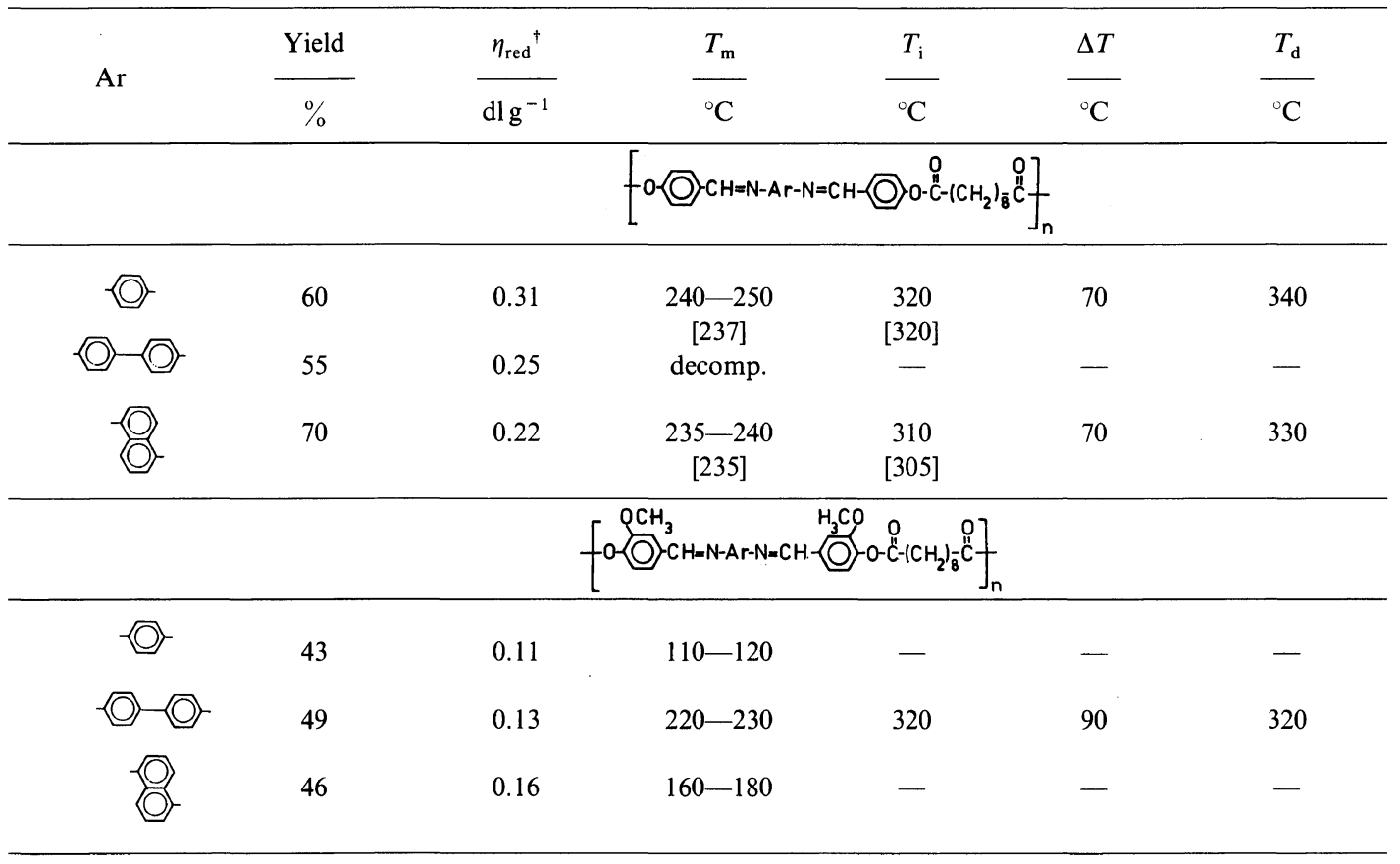

+ Determined at a concn of $1 \mathrm{~g} / 100 \mathrm{ml}$ in concd sulfuric acid at $20^{\circ} \mathrm{C}$. The temperatures detected by DSC appear in the square brackets.

$290^{\circ} \mathrm{C}$.

The polymers were observed for their phase transition temperatures and texture in a crystal phase using a polarizing microscope equipped with a hot stage (Boetius apparatus). For some polymers, the transition temperatures were determined by a differential scanning calorimeter (Perkin-Elmer DSC-2) at a heating rate of $10 \mathrm{Kmin}^{-1}$ under dry nitrogen flow.

The thermogravimetric measurements were performed in air at $1 \mathrm{~atm}$ on a derivatograph (F. Paulik, J. Paulik, L. Erdley) at a heating rate of $10 \mathrm{~K} \mathrm{~min}^{-1}$, using a $\mathrm{Pt}-\mathrm{Pt} / \mathrm{Rh}$ thermocouple.

\section{RESULTS AND DISCUSSION}

The structures of the dihydroxyazomethine compounds were confirmed by elemental and mass analysis and the IR and UV spectroscopy methods. The infrared spectra showed the presence of a band characteristic of $-\mathrm{CH}=\mathrm{N}$ bond at $1610-1640 \mathrm{~cm}^{-1},-\mathrm{OH}$ group at $3500 \mathrm{~cm}^{-1}, 1380 \mathrm{~cm}^{-1}$ and bands characteristic of aromatic rings at $830 \mathrm{~cm}^{-1}, 1450 \mathrm{~cm}^{-1}$, $1510 \mathrm{~cm}^{-1}$ and $1600 \mathrm{~cm}^{-1}$. In the UV spectra of the dihydroxyazomethine compounds, there were few absorption bands (Table I). Compounds having only phenylene ring exhibited four absorption bands, $E_{1}, E_{2}, B$, and $K$, and those with naphthalene rings, and additionally $\mathrm{R}$ band. ${ }^{7,8}$ The UV absorption bands of the dihydroxyazomethine compounds were very little influenced by structure. Compounds with methoxy backbone groups shifted little bathochromically compared to the proper bands of their unsubstituted analogs. The results of elemental and spectroscopic analyses confirmed the structure of the model compounds. In the infrared spectra of the model compounds, absorption bands characteristic of $-\mathrm{CH}=\mathrm{N}$ group $\left(1630 \mathrm{~cm}^{-1}\right)$ and characteristic 
D. SĘK

Table IV. Properties of dodecanedioic acid polyesters

\begin{tabular}{|c|c|c|c|c|c|c|}
\hline \multirow{2}{*}{$\mathrm{Ar}$} & Yield & $\eta_{\text {red }}{ }^{+}$ & $T_{\mathrm{m}}$ & $T_{\mathrm{i}}$ & $\Delta T$ & $T_{\mathrm{d}}$ \\
\hline & $\%$ & $\mathrm{dlg}^{-1}$ & ${ }^{\circ} \mathrm{C}$ & ${ }^{\circ} \mathrm{C}$ & ${ }^{\circ} \mathrm{C}$ & ${ }^{\circ} \mathrm{C}$ \\
\hline & 77 & 0.10 & $200-210$ & 300 & 90 & 310 \\
\hline & 50 & 0.18 & $240-250$ & 300 & 50 & 300 \\
\hline & 53 & 0.10 & $210-220$ & $\begin{array}{c}(280), 300 \\
{[270]}\end{array}$ & $(60), 80$ & 310 \\
\hline & & & O- $-\mathrm{CH}$ & $\begin{array}{l}\mathrm{H}_{3} \mathrm{CO} \\
\text { (O) }\end{array}$ & & \\
\hline$-\sqrt{c}$ & 46 & 0.10 & $\begin{array}{c}120-130 \\
{[125]}\end{array}$ & $(200), 300$ & $(70), 180$ & 300 \\
\hline (0) & 75 & partly sol. & $170-180$ & 300 & 120 & 330 \\
\hline C & 55 & 0.12 & $\begin{array}{l}140-160 \\
{[138,157]}\end{array}$ & $\begin{array}{c}(200), 310 \\
{[192]}\end{array}$ & $(40), 150$ & 310 \\
\hline
\end{tabular}

${ }^{\dagger}$ Determined at a concn of $1 \mathrm{~g} / 100 \mathrm{ml}$ in concd sulfuric acid at $20^{\circ} \mathrm{C}$. In parentheses appear pseudoisotropization temperatures. The temperatures detected by DSC are shown in the square brackets.

of carbonyl groups in the esters $\left(1750 \mathrm{~cm}^{-1}\right)$ were present along with absorption bands due to aromatic rings.

While melting the model compounds on a hot plate with a polarizing microscope, transitions from the solid to anisotropic liquid phase and mesophase to isotropic liquid were observed. The phase transition temperatures are shown in Table II. Melting points of the model compounds with phenyl and biphenyl structures between the azomethine groups (No. 1, 2 and 4, 5) differed very little but there was much difference in their temperatures of transition to isotropic liquids. The linear structures of the two phenyl rings influenced the rigidity and length of the molecule as evident from the higher stability of the mesophase. Condensed aromatic rings as in the case of 1,5-diaminonaphthalene derivatives (No. 3 and $\mathbf{6}$ ) caused a higher melting point of the proper model compound compared to the linear biphenyl structure but acted as destabilizing agents in the temperature range of the mesophase. The mesophase temperature range of the model compounds with pendant methoxy groups was narrower than that of the unsubstituted analogs.

The dihydroxyazomethine compounds were condensed with aliphatic diacid chlorides. The polyesters were soluble only in concd sulfuric acid, making it difficult to determine the molecular weight of the polymers. Molecular weight is one factor influencing phase transition temperatures. ${ }^{5}$ However the reduced viscosities of the polyesters investigated did not differ very much and the molecular weight of the polymers may not differ considerably. Table III shows the properties of the polyesters from sebacic acid. In a series of polyesters without pendant groups, strong anisotropy of the melt was observed in polymers having 1,4phenylene and 1,5-naphthylene moieties be- 
tween the azomethine groups in the dihydroxy compounds. The differences in their melting and isotropization temperatures were very little. In a series of sebacic acid polyesters with methoxy backbone groups, the strong anisotropy of the melt was observed in polyesters from di-4-hydroxy-3-methoxybenzylidene4,4'-diaminobiphenyl. In the sebacic polyester of di-4-hydroxy-3-methoxybenzylidene-1,5-diaminonaphthalene, a monotropic transition was observed but the optical anisotropy of the melt during cooling was weak. The melts of the sebacic acid polyesters exhibited nematic texture. Table IV shows the properties of the dodecanedioic acid polyesters. The longer aliphatic chains in the macromolecules cause a lowering of the melting temperatures of the polymers compared to the sebacic polyesters. The isotropization temperatures were also a little lower. The pendant methoxy groups causing a widening of the rigid part of the macromolecule brought about a lowering of the melting points of the sebacic and dodecanedioic acid polyesters compared with the unsubstituted analogs. The melts of the dodecanedioic acid polyesters exhibited nematic structures. The dodecanedioic acid polyesters with pendant methoxy groups having 1,4phenylene and 1,5-naphthalene rings between azomethine groups exhibit pseudoisotropic phenomena. The same was observed for the dodecanedioic acid polyester of di-4-hydroxybenzylidene-1,5-diaminonaphthalene. The pseudoisotropic phenomena were identified by the tendency of the polymer melt layer to become translucent on contact with the cover glass under microscopic observation. Near the pseudoisotropization temperatures the polymer melts contained no threads characteristic of the nematic phase and showed homogeneous color across large areas between crossed polarizers. Similar microscopic observations have been reported by Millaud et al. ${ }^{6}$ for the thermotropic nematic phase of polyazomethines. The pseudoisotropization temperatures of the polyesters investigated ad are presented in Table IV in parentheses.

Taking into consideration the mesophase temperature range, it may be said that the dodecanedioic acid polyesters having one phenylene ring between the azomethine groups exhibit a wider mesophase range than those with naphthalene rings. The influence of the aliphatic chain length was not very clear but in most cases, the dodecanedioic acid polyesters had a somewhat wider temperature mesophase range than the sebacic acid analogs. Usually, the mesophase range decreased with increasing flexible chain length. The reverse results observed for these polyesters may be explained by the fact that the longer aliphatic chain being the flexible structure element of macromolecule, has a stronger influence on the melting temperature than on the isotropization temperature causing the mesophase range to be wider. For most of the polyesters investigated, a darkening at the isotropization temperatures was observed and may possibly indicate the start of decomposition. The dynamic thermal analysis results confirmed the visual observation, i.e., the temperature at which the polymers loose $5 \%$ of their weight ( $T_{\mathrm{d}}$ in Tables III and IV) are very close to their isotropization temperatures.

For some polyesters calorimetric analyses were made. It was found that for thermally untreated samples the phase transitions were rather vaguely indicated and in the most cases, some transitions could be detected before melting points. This is probably related to the solid-solid transitions. Annealing the polyesters at the proper temperatures made it possible to read the spectrum more easily. The annealing temperatures influenced the transitions. For example, the DSC curve of dodecanedioic acid polyesters from di-4-hydroxy-3-methoxybenzylidene-1,5-diaminonaphthalene before and after annealing at $127^{\circ} \mathrm{C}$ for $1 \mathrm{~h}$, showed peaks at $138^{\circ} \mathrm{C}, 157^{\circ} \mathrm{C}$, and $192^{\circ} \mathrm{C}$, but after annealing the sample at $147^{\circ} \mathrm{C}$ for $14 \mathrm{~h}$, the peak at $138^{\circ} \mathrm{C}$ disappeared. The transition temperatures at which the maxi- 
mum peaks in the DSC curves for the thermally untreated polymers appeared, are presented in Tables III and IV in the square branckets. A more detailed calorimetric study in relation to $\mathrm{X}$-ray diffraction investigation is in progress and the results will be published in the near future.

\section{CONCLUSION}

Properties of sebacic and dodecanedioic acid polyesters having azomethine groups bound to aromatic rings in their main chains were described. Most of the poly(azomethineesters) obtained exhibit liquid crystalline properties and form the nematic mesophase. The relationship between the macromolecular chemical structure and phase transition temperature was established. It was confirmed that, using a longer aliphatic chain which is a flexibilizing element in the macromolecule or using monomers with pendant methoxy groups, lowers the melting and isotropization temperatures of the polyesters.

\section{REFERENCES}

1. S. L. Arora, J. L. Fergason, and T. R. Taylor, J. Org. Chem., 35, 4055 (1970).

2. Qi-Feng Zhon and R. W. Lenz, Polym. Prepr. Am. Chem. Soc. Div. Polym. Chem., 24(2), 255 (1983).

3. D. Sęk, Polym. J., 14, 173 (1983).

4. D. Sęk, Eur. Polym. J., in press.

5. A. Blumstein, S. Vilasagar, S. Pourathnam, S. B. Clough, R. B. Blumstein, and G. Maret, J. Polym. Sci., Polym. Phys. Ed., 20, 877 (1982).

6. B. Millaud, A. Thierry, C. Strazielle, and A. Skoulios, Mol. Cryst. Liq. Cryst. Lett., 49, 299 (1979).

7. E. A. Braude, Rep. Prog. Appl. Chem., 42, 105 (1945).

8. A. Burawoy, Tetrahedron, 2, 122 (1958). 